\title{
Robotic Colonic Resection and Reanastomosis in Gynecologic Surgery: Report of 4 Cases
}

\author{
Haider Mahdi, MD, Jessica Woessner, MD, Samantha Gonzalez-Ramos, MD, \\ Maral Malekzadeh, DO, Mehdi Moslemi-Kebria, MD \\ Gynecologic Oncology Division, Ob/Gyn and Women's Health Institute, Cleveland Clinic, Cleveland, OH, USA \\ (Drs. Mahdi, Woessner, Gonzalez-Ramos, Moslemi-Kebria). \\ Touro College of Osteopathic Medicine, New York, NY, USA (Dr. Malekzadeh).
}

\begin{abstract}
Introduction: Colonic resection in gynecologic surgery, most commonly in the field of gynecologic oncology, is traditionally performed through open laparotomy. Most cases are performed during cancer debulking in either primary or recurrent settings. Other less common indications include resection of ovarian remnants or endometriotic lesions densely adherent to the large bowel, commonly the rectosigmoid colon.

Case Description: We describe 3 patients with ovarian remnant syndrome and 1 patient with ovarian cancer who underwent successful robotic surgery that included colonic resection and reanastomosis. The mean operative time, blood loss, and hospital stay were 216 minutes, $162.5 \mathrm{~mL}$, and 6.25 days, respectively, with no significant perioperative complications.
\end{abstract}

Discussion: Minimally invasive robotic colonic resection with reanastomosis is a feasible and safe approach in appropriately selected cases when performed by an experienced surgeon.

Key Words: Robotic, Colon resection, Ovarian remnant syndrome, Ovarian cancer.

Citation Mahdi H, Woessner J, Gonzalez-Ramos S, Malekzadeh M, Moslemi-Kebria M. Robotic colonic resection and reanastomosis in gynecologic surgery: report of 4 cases. CRSLS e2014.002160. DOI: 10.4293/CRSLS.2014.002160.

Copyright (c) 2015 by SLS, Society of Laparoendoscopic Surgeons. This is an open-access article distributed under the terms of the Creative Commons Attribution-Noncommercial-ShareAlike 3.0 Unported license, which permits unrestricted noncommercial use, distribution, and reproduction in any medium, provided the original author and source are credited.

Address correspondence to: Mehdi Moselmi-Kebria, Ob/Gyn and Women's Health Institute, Cleveland Clinic, 9500 Euclid Ave, Cleveland, OH 44195, USA. Telephone: (216) 445-6325, Fax: (216) 445-6325, E-mail: mkebria@gmail.com

\section{INTRODUCTION}

In 2000 the da Vinci robotic system (Intuitive Surgical, Sunnyvale, California) was approved for use in both adult and pediatric surgical cases. ${ }^{1}$ Although there is some controversy surrounding the use of the robotic system because of its cost, the benefits can outweigh the drawbacks, especially in complicated cases. The dexterity provided by the full-fulcrum instrumentation, as well as the 3-dimensional visualization at the console, makes the da Vinci system even more beneficial in complicated gynecologic cases when compared with traditional laparoscopy. ${ }^{2}$

Studies in the colorectal field have shown that the robotic approach is feasible and is associated with favorable surgical outcomes, as well as a lower rate of conversion to laparotomy, when compared with traditional laparos- copy. ${ }^{3,4}$ Colorectal involvement is often seen in 3 gynecologic conditions: ovarian remnant syndrome, advanced endometriosis, and ovarian cancer. These disorders often require bowel resection for complete disease resection.

Ovarian remnant syndrome is a disease in which patients are found to have residual ovarian tissue left behind after previous oophorectomy procedures. The etiology most commonly linked with this disease is endometriosis, particularly invasive endometriosis. Several studies have shown that advanced endometriosis often involves the gastrointestinal system, especially the rectum and sigmoid colon. In such cases the recurrence rate of endometriosis or ovarian remnant syndrome is highest when complete resection of the involved portion of the bowel is not completed. ${ }^{4,5}$ 
Table 1.

Clinical Characteristics of 4 Patients Who Underwent Robotic Colonic Resection With Additional Other Procedures

\begin{tabular}{|c|c|c|c|c|c|}
\hline Variable & Case 4 & Case 1 & Case 2 & Case 3 & Mean \\
\hline Age, y & 46 & 44 & 67 & 78 & 58.75 \\
\hline Diagnosis & Ovarian remnant syndrome & $\begin{array}{l}\text { Ovarian remnant } \\
\text { syndrome }\end{array}$ & $\begin{array}{l}\text { Ovarian remnant } \\
\text { syndrome }\end{array}$ & $\begin{array}{l}\text { Recurrent } \\
\text { ovarian cancer }\end{array}$ & \\
\hline Gravida/parity & $4 / 2$ & $3 / 3$ & $2 / 2$ & $5 / 3$ & \\
\hline Extent of surgery & $\begin{array}{l}\text { Robotic resection of bilateral } \\
\text { ovarian remnants, bilateral } \\
\text { parametrectomy, upper } \\
\text { vaginectomy, bilateral } \\
\text { ureterolysis, wedge } \\
\text { resection of sigmoid colon, } \\
\text { and bladder peritonectomy }\end{array}$ & $\begin{array}{l}\text { Robotic resection of } \\
\text { ovarian remnant } \\
\text { syndrome en bloc } \\
\text { with rectosigmoid } \\
\text { resection and end- } \\
\text { to-end primary } \\
\text { reanastomosis, } \\
\text { bilateral } \\
\text { ureterolysis, upper } \\
\text { vaginectomy, and } \\
\text { extensive pelvic } \\
\text { dissection }\end{array}$ & $\begin{array}{l}\text { Robotic en bloc resection } \\
\text { of left pelvic mass and } \\
\text { portion of proximal } \\
\text { sigmoid colon, with side- } \\
\text { to-side stapled } \\
\text { colocolostomy and left } \\
\text { ureterolysis }\end{array}$ & $\begin{array}{l}\text { Robotic posterior } \\
\text { pelvic } \\
\text { exenteration } \\
\text { including radical } \\
\text { trachelectomy, } \\
\text { low anterior } \\
\text { rectal resection, } \\
\text { and end-to-end } \\
\text { stapled } \\
\text { colorectostomy }\end{array}$ & \\
\hline $\begin{array}{l}\text { Operative time, } \\
\text { min }\end{array}$ & 200 & 318 & 153 & 193 & 216 \\
\hline $\mathrm{EBL},{ }^{\mathrm{a}} \mathrm{mL}$ & 300 & 200 & 50 & 100 & 162.5 \\
\hline $\begin{array}{l}\text { Length of } \\
\text { hospital stay, d }\end{array}$ & 9 & 5 & 6 & 9 & 6.25 \\
\hline $\begin{array}{l}\text { Perioperative } \\
\text { complications }\end{array}$ & None & None & $\begin{array}{l}\text { Postoperative atrial } \\
\text { fibrillation }\end{array}$ & $\begin{array}{l}\text { Postoperative } \\
\text { atrial fibrillation }\end{array}$ & \\
\hline $\begin{array}{l}\text { Final pathologic } \\
\text { diagnosis }\end{array}$ & $\begin{array}{l}\text { Ovarian tissue, no } \\
\text { malignancy }\end{array}$ & $\begin{array}{l}\text { Endometriosis, } \\
\text { ovarian tissue, no } \\
\text { malignancy }\end{array}$ & $\begin{array}{l}\text { Rete cystadenoma, } \\
\text { mesovarium, no } \\
\text { malignancy }\end{array}$ & $\begin{array}{l}\text { High-grade } \\
\text { carcinoma }\end{array}$ & \\
\hline
\end{tabular}

${ }^{\mathrm{a}} \mathrm{EBL}=$ estimated blood loss.

In this case series, we describe 4 patients and their experience with successful robotic colonic resection.

\section{CASE DESCRIPTION}

\section{Case 1}

A 44-year-old woman, gravida 3, para 3, had chronic pelvic pain that began in 2003. After failure of medical therapy for presumed endometriosis, the patient underwent a total abdominal hysterectomy with bilateral salpingo-oophorectomy in 2008. Her pain continued despite the operation, and she was treated with leuprolide acetate for a short period. Laboratory evaluation showed a premenopausal level of follicle-stimulating hormone of $5.8 \mathrm{mU} / \mathrm{mL}$, indicating retained ovarian tissue. Pelvic magnetic resonance imaging showed a $4 \times 4-\mathrm{cm}$ left complex cystic adnexal mass embedded in the sigmoid colon. In November 2010, the patient underwent robotic resection for ovarian remnant syndrome en bloc with rectosigmoid resection and end-toend primary reanastomosis, bilateral ureterolysis, upper vaginectomy, and extensive pelvic dissection. Intraoperatively, a mass embedded within the sigmoid mesentery in the retroperitoneal space was identified; it was densely adherent to the ureter and sigmoid colon, necessitating en bloc resection of the mass with the rectosigmoid, which was achieved robotically. The operative time was 318 minutes and estimated blood loss was $300 \mathrm{~mL}$, with no perioperative complications. She was discharged home 5 days after surgery after having flatus and a bowel movement (Table 1).

The final pathologic examination showed endometriosis involving the colonic muscularis propria and pericolic tissue, with ovarian tissue with hemorrhagic cystic follicles and adhesions to the bowel wall. There was no evidence of malignancy within the specimens. 


\section{Case 2}

A 67 -year-old woman, gravida 2, para 2, with a remote history of endometriosis in 1976 was evaluated for new complaints of abdominal and pelvic pain in 2012. She had undergone a total abdominal hysterectomy with bilateral salpingo-oophorectomy in the 1970s. Imaging showed septate loculated masses containing layering debris; the left-sided mass measured $4 \times 6 \mathrm{~cm}$, and the right-sided mass measured $4.6 \times 6 \mathrm{~cm}$. In May 2012 the patient underwent robotic en bloc resection of the left pelvic mass and a portion of the proximal sigmoid colon, with endto-end stapled reanastomosis and left ureterolysis because it was not possible to safely dissect the mass away from the colon. The operative time was 153 minutes and estimated blood loss was $50 \mathrm{~mL}$, with no perioperative complications except for atrial fibrillation that was resolved on postoperative day 1 . The patient was discharged home 6 days after surgery after having flatus and a bowel movement (Table 1).

The final pathologic examination yielded benign findings with no evidence of malignancy.

\section{Case 3}

A 78-year-old woman, gravida 5, para 3, presented initially for evaluation of pelvic pain in January 2013. Imaging showed several complex-appearing masses in the pelvis with no identification of normal ovarian tissue. In March 2013 a laparoscopic abdominal pelvic survey showed a solid-appearing right ovary, multiple pelvic masses, small nodules throughout the peritoneum, and free fluid in the pelvis. The patient then underwent a robotic debulking procedure including supracervical hysterectomy, bilateral salpingo-oophorectomy, and peritoneal and omental biopsy. The debulking was suboptimal with a residual 3- to $4-\mathrm{cm}$ plaque at the cul-de-sac involving the rectum and posterior cervix. Pathologic findings were consistent with a high-grade serous carcinoma, and the patient was diagnosed with stage III-B serous adenocarcinoma of the ovary.

The patient's procedure was followed with an adjuvant chemotherapy regimen of carboplatin and paclitaxel for 4 total cycles. She was then taken to the operating room for an interval robotic cytoreductive surgical procedure. She underwent posterior pelvic exenteration including a radical trachelectomy, low anterior rectal resection, and endto-end stapled colorectostomy in September 2013. The operative time was 193 minutes and estimated blood loss was $100 \mathrm{~mL}$, with no perioperative complication except for cardiac arrhythmia necessitating intensive care unit admission that was resolved on postoperative day 2. She was discharged home 9 days after surgery after having flatus and a bowel movement (Table 1).

Pathologic examination of the cervix showed 2 foci of high-grade carcinoma with chemotherapy effect involving the posterior cervical wall with negative margins. Evaluation of the rectum showed a focus of high-grade carcinoma with chemotherapy effect involving the muscularis propria, also with negative margins.

\section{Case 4}

A 46-year-old woman, gravida 4, para 2, presented with a long-standing history of pelvic pain. The first surgical intervention for this pain was performed in June 2009, at which time she underwent hysterectomy. In 2012 her pain returned and she was found to have an adnexal mass. She underwent a laparotomy with removal of the mass. The following year, pain again developed and she was noted to have an adnexal mass on imaging. She underwent a laparoscopy that was converted to open lysis of adhesions and removal of what appeared to be her bilateral tubes and ovaries in March 2013. The relief of her symptoms was again short-lived, and in November 2013 she was again found to have adnexal masses on imaging. Pelvic magnetic resonance imaging showed bilateral ovarian remnants. The left remnant measured $1.8 \times 1.6 \mathrm{~cm}$, and the right remnant measured $1.5 \times 0.8$ $\mathrm{cm}$, with a dilated tubular structure in the right adnexa that measured up to $9 \mathrm{~mm}$ in diameter. Tumor markers were negative, with CA-125 of 11 and CEA of 1.0. The patient was taken to the operating room and underwent robotic resection of the bilateral ovarian remnants, bilateral parametrectomy, upper vaginectomy, bilateral ureterolysis, wedge resection of the sigmoid colon, and bladder peritonectomy in November 2013. The operative time was 200 minutes and estimated blood loss was $200 \mathrm{~mL}$, with no perioperative complications. The patient stayed in the hospital for 5 days and was discharged home after having flatus and a bowel movement (Table 1).

The final pathologic examination showed no evidence of malignancy. The resected portion of the patient's sigmoid colon was found to have ovarian tissue present in the form of fragments of benign dense fibroid tissue with follicles present.

\section{OPERATIVE PROCEDURE}

The patient was placed in the dorsal lithotomy position. Robotic ports were placed in standard fashion, and the 


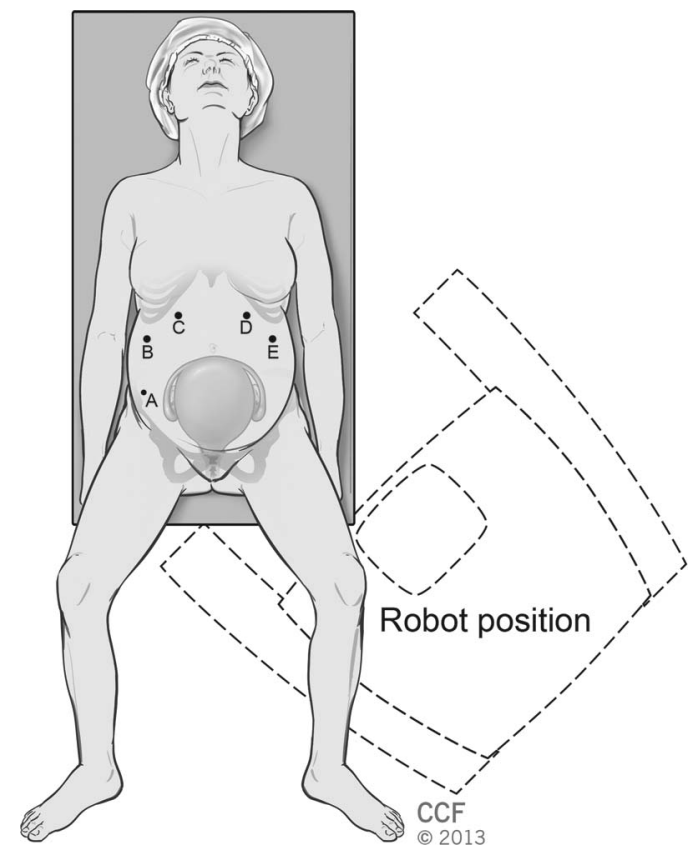

Figure 1. Robot docking. The robot is docked on the left side of the patient, with port placements as shown: 12-mm bedside assistant port (A), 8-mm robotic port (B, D, E), and 12-mm camera port (C). Reprinted with permission from the Cleveland Clinic Center for Medical Art and Photography. Copyright 2013. All rights reserved.

robot was side docked (Figure 1). The retroperitoneal space was dissected, and the perirectal and perivesical spaces were developed on both sides. The bladder and rectum were separated from the vaginal cuff by sharp dissection. The ureter was mobilized and followed down to its insertion into the bladder on both sides. On the left side, dense adhesions between the ureter and the ovarian remnant were taken down with scissors. The mesentery of the rectum was cauterized with a vessel sealer device. A $60-\mathrm{mm}$ endosurgical articulating stapler introduced through the bedside assistant port was used to transect the rectum above the level of the vaginal cuff and below the level of the ovarian remnant segment. The mesentery of the sigmoid colon above the level of involvement with the ovarian remnant was cauterized with a vessel sealer device. The sigmoid colon was transected above the level of involvement with the ovarian remnant with a linear stapler. A colpotomy was performed, and the specimen (including the rectum, sigmoid, and ovarian remnant) was delivered through the vagina without difficulty and submitted for pathologic analysis. The staple line of the proximal segment of the anastomosis was cut with scissors, and the anvil of the end-to-end stapling device, was placed in the lumen and secured with a purse-string suture using No. 2-0 Prolene (Ethicon, Somerville, New Jersey). The end-to-end anastomosis stapler was placed into the anus and advanced into the rectal stump. End-toend anastomosis was performed, and 2 complete donuts were removed and examined. The rectum was insufflated with a proctoscope without evidence of an air leak. A pelvic drain was placed, and the vaginal cuff was closed with No. 0 Vicryl (Ethicon) in a running fashion and reinforced with a second suture layer (video available upon request).

\section{DISCUSSION}

There are several scenarios in the field of gynecology/ gynecologic oncology in which bowel resection is necessary for appropriate treatment of the patient and eradication of disease, including cases of invasive endometriosis or ovarian remnant syndrome, as well as cases of cancer debulking. In this report we show that minimally invasive colonic resection with reanastomosis is feasible through a robotic platform if performed by an experienced gynecologic surgeon. In all of the patients described in this report, we were able to successfully complete the surgical procedures in a minimally invasive manner without conversion to open laparotomy.

Colorectal surgery as a whole has made many advancements in recent years, especially in the field of minimally invasive surgical techniques. In 2001 Weber et $\mathrm{al}^{3}$ performed the first robotic-assisted colon resection using the da Vinci system. They were able not only to show the feasibility of robotic bowel resection but also to suggest its superiority over the traditional laparoscopic technique because the da Vinci system allowed a 3-dimensional operative field, better ergonomics for the surgeon, and a full range of motion of instrumentation.

D'Annibale et $\mathrm{al}^{6}$ were able to show, through a case series of 50 cases in 2012, that not only does the da Vinci system allow for successful completion of colectomies in benign disease, it also allows adequate resection for oncologic cases including lymph node dissection and clear margins. In their study 50 patients with known right-sided colon cancer underwent either staging or debulking procedures with the da Vinci surgical system. All involved cases were successfully completed using the robotic platform, with no conversion to laparotomy. The median operative time was 223.50 minutes, which is comparable with that of their open counterparts. The mean operative time in our 4 cases was 216 minutes, consistent with the report by D'Annibale et al. 
In an overall review of current literature on robotic colon resection, Antoniou et $\mathrm{al}^{7}$ identified 39 case series or comparative nonrandomized studies in 2012. They found that application of the da Vinci surgical system resulted in an open conversion rate of $1.1 \%$ and $3.8 \%$ when applied to right and left colectomies, respectively. The conversion rate noted for anterior resection was only $0.4 \%$. From this review, Antoniou et al also concluded that robotic bowel resection was feasible with a low conversion rate to laparotomy and favorable morbidity rates of $13.4 \%$ and $15.1 \%$ for right and left colectomies, respectively.

Bowel resections are often required in the field of gynecology/gynecologic oncology, particularly when looking at invasive endometriosis, ovarian remnant syndrome, and cancer debulking procedures. Throughout the past decade, several studies have shown the superiority of minimally invasive surgery over open laparotomy when looking at patient satisfaction, blood loss, length of hospital stay, and patient recovery time..$^{1,2,5}$ Further comparisons between robotic surgery and traditional laparoscopy have shown similar operative times in the hands of skilled surgeons, as well as a decreased rate of conversion to laparotomy., 3 , Our case series represents one of first case series reporting the feasibly of successfully performing minimally invasive colonic resection and reanastomosis through the robotic platform in 3 patients with ovarian remnant syndrome and 1 case with secondary cytoreductive surgery for ovarian carcinoma without conversion to open laparotomy. The mean blood loss was $162.5 \mathrm{~mL}$, and the mean length of hospital stay was 6.5 days until having flatus and a bowel movement. This approach should be considered in appropriately selected patients and performed by an experienced surgeon who is familiar with these procedures and robotic technology. Our approach for colonic resection was slightly different from the colorectal approach because we started retroperitoneally and developed the perivesical and perirectal space first, before proceeding with colonic resection (lateral to medial approach).
In conclusion, the application of the da Vinci surgical system to the field of gynecology/gynecologic oncology has been beneficial both to the surgeon and to the patient. With the high prevalence of cases requiring bowel resection particularly in patients with endometriosis, ovarian remnant syndrome, and cancer debulking, the da Vinci surgical system might be considered for complicated cases that might require bowel resection with the ultimate goal of complete eradication of the disease. The described cases were performed by a gynecologic oncologist who is familiar with the robotic platform and bowel resection. However, this approach can also be coordinated as a combined procedure with colorectal and gynecologic surgeons especially in situations in which the gynecologic surgeon does not feel comfortable performing the colonic resection.

\section{References:}

1. Yu H, Friedlander D, Patel S, Hu J. The current status of robotic oncologic surgery. Cancer. 2012;63(1):46-56.

2. Krill L, Bristow R. Robotic surgery: gynecologic oncology. Cancer J. 2013;19(2):167-176.

3. Weber P, Merola S, Wasielewski A, Ballantyne G. Telerobotic-assisted laparoscopic right and sigmoid colectomies for benign disease. Dis Colon Rectum. 2002;45:1689-1696.

4. Neme R, Schraibman V, Okazaki S, et al. Deep infiltrating colorectal endometriosis treated with robotic-assisted rectosigmoidectomy. JSLS. 2013;17:227-134.

5. Zapardiel I, Zanagnolo V, Kho RM, Magrina JF, Magtibay PM. Ovarian remnant syndrome: comparison of laparotomy, laparoscopy and robotic surgery. Acta Obstet Gynecol Scand. 2012; 91(8):965-969.

6. D'Annibale A, Pernazza G, Morpurgo E, et al. Robotic right colon resection: evaluation of first 50 consecutive cases for malignant disease. Ann Surg Oncol. 2010;17(11):2856-2862.

7. Antoniou S, Antoniou G, Pointner R, Granderath F. Robotassisted laparoscopic surgery of the colon and rectum. Surg Endosc. 2012;26(1):1-11. 